\title{
CSR practices in countries in transition: the case of Morocco
}

\author{
Asmae OURDI ${ }^{1,2^{*}}$, Abdellatif TAGHZOUTI ${ }^{2,}$ Salmane BOUREKKADI ${ }^{3}$ \\ ${ }^{1}$ TREE, UMR CNRS 6031, Pau University, Pau France. \\ ${ }^{2}$ Sidi Mohamed Ben Abdellah, Fez Morocco. \\ ${ }^{3}$ University of poitiers, France.
}

\begin{abstract}
This research aims to present a global vision on corporate social responsibility (CSR) in the context of a country in transition such as Morocco, CSR is defined as a set of economic practices characterized by transparency, ethical transactions, openness to the outside world and respect for employees and society. while placing great importance on the environment. In the context of climate change and the collapse of biodiversity, corporate social responsibility brings sustainable value to society and shareholders. For this article, we relied on an analytical approach, collecting, analysing, and discussing academic papers relating to the subject matter, and more specifically focussing on a few cases in Morocco. Among the results we have achieved, is the identification of some of the challenges facing the application of corporate social responsibility in Morocco.
\end{abstract}

Keywords: Corporate Social Responsibility, Sustainable Development, Morocco, Stakeholder Management, Social Responsible Management.

\section{INTRODUCTION}

The internationalization of the economy leads business leaders to face many opportunities but also many challenges. In this sense, we focus on CSR practices in Moroccan companies on the basis of a critical study drawn from several carefully selected articles, given the scarcity of studies done on the field of CSR in Morocco. Indeed, CSR implies that a company should not only care about its profitability and growth, but also about its environmental and social impacts. It should be more attentive to the concerns of its stakeholders: employees, shareholders, customers, suppliers ${ }^{[1]}$.

In Morocco, CSR is now an unavoidable theme, driven both by civil society but also by the companies themselves and their stakeholders ${ }^{[2]}$. It is intended as the means by which companies claim their responsibilities towards society and the environment in which they operate and evolve.

Our present article is dealing with the concept of corporate social responsibility (CSR) in the Moroccan context. We consider the example of OCP case which is considered as very important by most of the authors in this field.

\footnotetext{
* Corresponding author: asmae.ourdi1@gmail.com
}

\section{Background of CSR in Morocco}

Quite a while back, King Mohamed VI launched in 2005 the National Initiative for Human Development (INDH) ${ }^{[3]}$. It is a methodology which plans to build up the social and democratic side just as decentralization and to change the financial and social circumstances of poor people. In a similar rationale, Moroccan organizations are urged to contribute to this public goals. Accordingly, the idea of CSR (corporate social responsibility) has become a public and key reference to which organizations can allude. Another request is forced on Moroccan organizations with the globalization of the economy, which, therefore, creates an opening of business sectors and the appearance of new worldwide contenders. What truly has the effect of supporting the development of innovation and firms cross-borders association. Under these conditions, we are observer to the launch of a few chances to urge CSR into firms and administrative practices in Morocco. Regardless of this, the CSR development in Morocco is confronted with switches and obstructions. 
In Morocco, corporate social obligation has been influenced by worldwide organizations and neighborhood accomplices in this field. Its development is upheld by good broad conditions just as lawful and institutional changes including the National Initiative for Human Development (INDH), change of the administrative structure and the normalization development ${ }^{[4]}$.

In May 2005, the National Initiative for Human Development, launched by King Mohammed VI, has the principal objective of establishing the frameworks for a multi-year public program to incorporate social destinations into venture choices. In this argument, the royal speech is a solid and positive message to the extent that it establishes a genuine vector of prompting to private activities: «The social duty of financial backers has as a condition the social obligation of organizations. In such manner, we are following with interest and fulfillment the activity of Moroccan organizations which have willfully taken this path» (Extract from the Message of H.M. the King to the third edition of the "Integrals of Investment", 2005) ${ }^{[5]}$.

In concrete terms, the INDH offers a framework of reference and funding to economic actors (25 million euros for the first five years of its launch) to stimulate social dynamics in the economic context which is in full development.

Moreover, in 2004 we saw the birth in the legislative framework of a new labor code which serves to strengthen the connection with human rights and international labor conventions.

One of the strengths of this new code remains in social dialogue and also with the institution of mediation, arbitration, consultation and periodic collective bargaining mechanisms. Again, this code also offers tools for adapting certain measures to sectoral and organizational particularities. In principle, these are internal instruments such as: the works council, the health and safety committee, the company agreement and the branch collective agreement.

In addition, Morocco is in full movement of normalization The Ministry of Industry, Trade and Economy Upgrade shows significant market demand in this area. Thus, many Moroccan standards are adopted, including concerning the management of social aspects in the company through the standard NM00.5.600 (Management system of social aspects in the company).

This standard refers to the principles set out in SA 8000 (Social Accountability 8000, an international standard developed in 1989 by Social Accountability International in the model of ISO standards) and to the eleven conventions of the International Labor Organization. It takes into account local regulations and the labor code and is compatible with other management precepts (quality, environment and safety). Also, this standard specifies the overall positions for the establishment and management of a social audit system.

Indeed, Morocco is a member of the French-speaking commission for the preparation of the ISO 26000 standard on social responsibility. This standardization action reflects a dynamic orientation that tends towards the integration of social issues into management systems and a real determination to install the normative bases to go beyond legal obligations and participate in creating an environment marked by trust between the various socioeconomic actors.

At the level of this paper, we follow a method of exploratory data analysis whose main character is descriptive. The present analysis is based on a set of data carefully selected and collected from several articles and research works that deal with the subject. Our research is based on recent studies that we selected and chose carefully, referring to interviews with people who are active and responsible at the level of associations advocating the involvement of companies in the allocation of social responsibility in their strategy.

The articles and research works that we used meet a set of criteria such as the level of indexation of their publication journal, the date of publication and the credibility of its authors as well as their experience in the field of corporate social responsibility.

We can confirm that the articles dealing with the case of Morocco are rare, for this we found difficulties in carrying out this work, while the choice of Morocco is based on several critics:

1) Morocco's advanced economic position.

2)The motivation of Moroccan companies to join globalization.

3) Opening up Morocco to multinational companies.

4) Support of Moroccan companies by sharing data.

5)The availability of representatives to Moroccan companies to answer questions from our team.

\section{Presentation and analysis of highly significant papers}

In this study, we will concentrate on research conducted on Moroccan companies. We propose to consider the Social Responsibility approach of the OCP (Office Cherifian des Phosphates), which is one of the major Moroccan companies. We will analyze the development of this company (OCP) and its CSR approach, within a Moroccan economy in full change, also we will talk about social impact pursued by Moroccan companies and Moroccan businesses' environmental responsibilities.

\subsection{The case of The Office Cherifien des Phosphates}

The case of OCP shows us the development of a CSR approach that changes due to the influence of external constraints. Shifting from a paternalistic logic to an approach of social responsibility is in this case the result of pressures from the national and international environment.

Indeed, the OCP is entering a privatization movement. Its legal structure and its management methods inherited from old paternalism are also changing. The change in the legal environment may have been the trigger. Thus, the controversy concerning the taxation of the Cherifian phosphate office shows that the tax services are gradually considering the OCP as an "ordinary" business. 
This is how the latter is forced to pay taxes on community service that it has funded, but, in return, it has the possibility of offloading the payment of pensions and soon the health expenses of its employees. The state, in this way, reminds OCP of its capital role which focuses on the extraction and development of phosphates for which it holds the monopoly of exploitation in Morocco. The change in legal status and in the composition of capital show that the responsibilities of the OCP tend to be similar to those of Moroccan companies. The internal functioning of the company can only adjust to this new situation.

The OCP changes its culture, moving from a technical culture to another of a managerial type. Thus, the recruitment methods and also the workers profiles are specialized. Paternalistic orientations are abandoned ${ }^{[6]}$. Finally, the management of the OCP is developing closely with the changes in status. There is no better example than the evolution in the recruitment of engineers and in the modification of their role within the company. Thus, the technical culture is exchanged by a technical managerial biculture at the OCP. These changes are certainly positive in terms of profitability, but they have huge consequences on the culture of the OCP: the feeling of belonging weakens on the one hand, and a financial logic is imposed on the other hand. Henceforth, the OCP is directed by a strategy of adaptation to world market forces and no more by self-centered principles around Moroccan balances ${ }^{[7]}$. Simultaneously, the organization summons a CSR approach, which is inadequately formalized, however which is like those applied by other globalized organizations, which are quick to regard the assumptions for numerous partners. The scientists saw that ecological concerns were progressively considered in Morocco.

The company is responsible for limiting the ecological damage caused by the exploitation of phosphates. Its economic, social and planning responsibilities towards the territories, are shown in figure 1.

Figure 1. the various components of CSR, which will be presented in the following manner:

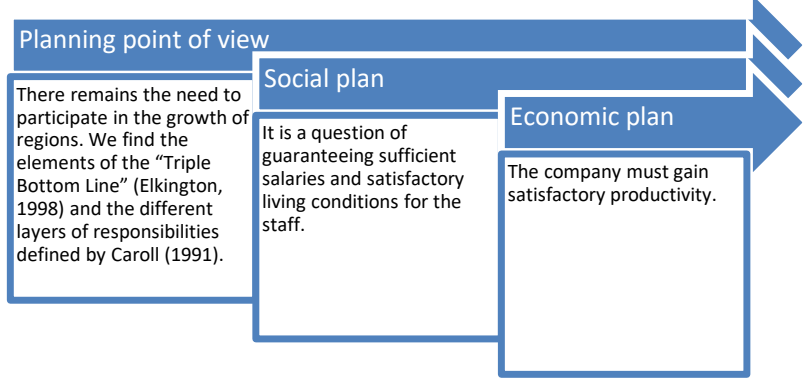

The data accumulated is different and shows the development of this organization under the limitations of outer pressing factors because of changes in its current circumstance and should change its lead and working techniques. The appropriation of CSR concerns is important for this essential variation. This case shows the job of social guideline of CSR featured by Gond and Igalens $(2008)^{[8,9]}$.

\subsection{Impact on social responsibility (CSR) strategies pursued by moroccan companies}

Despite anecdotal proof of the personal characteristics (beliefs, goals, traits) of CEOs of organizations who have an alliance with a socially responsible corporation, the relationship between the leader's orientation and his or her socially responsible employees is technically poorly known. This assignment's main achievements are presented in three steps. First, the researchers add to the literatures on strategic leadership and CSR by revealing the connection between Moroccan industries' social responsibility efforts and the leadership styles of those in charge.

Second, the researchers hope to fill a void in the CSR literature by conducting an empirical test of the relationship between strategic leadership and CSR strategies, which has been very helpful in investigating the central role of the leader in addressing a firm's commitment to social and environmental issues and has also been free of any hypotheses on the individual determinants of CSR strategies ${ }^{[9]}$.

The authors of the articles we have exploited would like to present some limitations that have arisen as a result of the study's evolution, especially at the conceptual or methodological level. Furthermore, the findings of this study demonstrated that it is difficult to account for the variation in CSR strategies since they are heavily reliant on other variables found at higher levels of research, such as institutional influences. We couldn't calculate things like institutional causes. Multiple divisions of research, such as executive committees or board members, may have been included in the report they wanted to do. However, the variables examined in this analysis have their own limitations, as they only have a partial image of an accessible leadership role.

While recent research has demonstrated that openness can be assessed as a combination of age, seniority, and academic context, the extent to which other markers of a leader's open orientation, such as professional career, scope of experience, and foreign experience, can be accommodated as a formative or reflective construct has yet to be established ${ }^{[10]}$. Other distinguishing characteristics that may indicate the leader's flexible orientation, such as experience in several businesses or sectors, as well as experience in non-profit organizations, may also be considered by researchers (Geletkanycz and Hambrick, 1997).

Furthermore, this study examined partnerships that were solely based on the CSR solution as a strategic option for incorporating positive CSR programs. There was no correlation found between management orientation and the company's social or environmental shortcomings in relation to its different stakeholders. Nonetheless, the data gathered in this study would be useful not only for future research on the precursors and consequences of corporate social non-trust, but also for observational analyses on the extent of variation of organizational social acrobatics across policy realms, allowing for a more straightforward test of DiMaggio and Powell's (1983) establishment of corporate social nontrust. Furthermore, in order to put the step-by-step 
approach to CSR to the test [11], More studies into the various approaches to greater corporate social responsibility is being considered by researchers. It is possible, for example, to investigate how organizations participate in CSR techniques by minimizing negative externalities and then intensifying CSR programs in a specific field before going on to numerous and extensive ranges, or what other evolutionary directions are possible ${ }^{[12,13]}$.

\subsection{Moroccan businesses' environmental responsibilities}

Morocco had a population of over 5 million by the beginning of the twentieth century, a number that has increased fivefold in just one century to 33.4 million in 2014. Indeed, the continent's rapid population growth is putting pressure on water supplies, forest resources, coastlines and environmental sustainability. The prospects of a shrinking population in the coming years raise concerns about the sustainability of the country's economic growth. The Moroccan state has developed a strategy that contributes to the protection of the environment, as it is very aware of climate change and its impact on economic and social development.

The Moroccan state has embarked on a logic of Corporate Social Responsibility (CSR), to encourage private actors to position themselves in favour of environmental protection. A commitment that has pushed economic actors to develop solid skills in terms of information gathering, strategic analysis, mapping of risks associated with stakeholders. Morocco has put in place several training courses related to the ecological transition, in order to accompany this participatory vision of the private sector and civil society.

For example, after the creation of its Corporate Social Responsibility label in 2006, the General Confederation of Moroccan Enterprises (CGEM) collaborated extensively with the United Nations Development Programme (UNDP) to train the executives of its member companies on the issue of climate finance. Also, structured associations and think tanks have been created, aiming to raise awareness of the Moroccan culture of corporate social responsibility ${ }^{[15]}$.

In order for companies to be environmentally responsible, they will be obliged to apply ecological knowledge according to the ISO26000 principles. In order to do so, here are the 10 actions that all companies must implement to fight against climate change ${ }^{[16]}$.

Figure2: 10 Actions Companies Can Take for the Climate

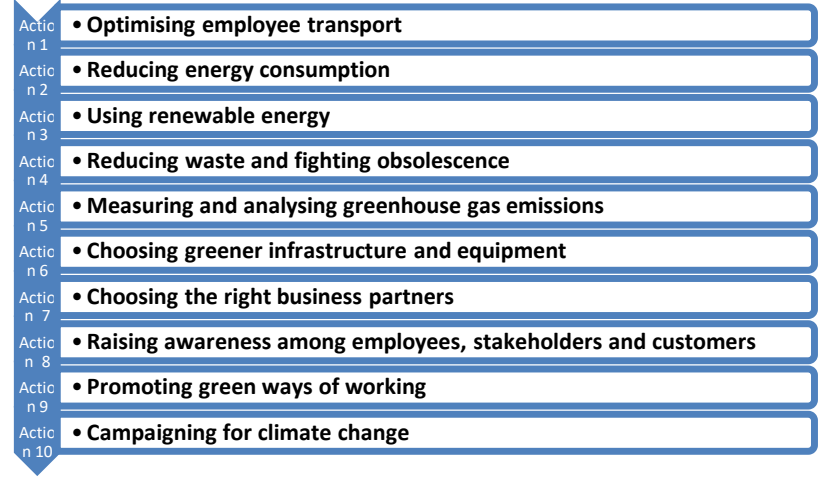

As a result of globalization, big Moroccan enterprises, many of which are subsidiaries of foreign conglomerate, are increasingly incorporating environmental considerati ons into their development strategies.

ST Micro Electronics started this trend three years ago. It was the first Moroccan firm to receive ISO 14001 certifi cation, an international standard for environmental mana gement. Since then, seven other businesses have followed suit. Bayer Maghreb, Holcim, Clack Gum, Manifacturing Advance, JLEC, and Ciments du Maroc are the companies involved. While under receivership, Goodyear was also certified.

The responsibility towards the protection of the environment is a responsibility of all the components of the company, including the companies in a first degree, the thing which ensures the safety of the employees and the increase of turnover of the companies, while Moroccan companies have participated in the protection of the environment for the motivations that we have presented

\section{Result and discussion}

CSR in Morocco encounters several obstacles that compromise its implementation in management systems despite the multiple efforts made to support it, according to Filali Maknassi (2009), these elements are mainly: the qualification of the personnel, the lack of information and of financial resources ${ }^{[17]}$. which discover their causes in: Morocco's cultural heritage is founded on traditional paternalistic beliefs ${ }^{[18]}$. This 'paternalistic entrepreneurship' culture reduces economic success to cost-cutting and positions authority at the center of the management-employee relationship. It prevents the emergence of stakeholder pressures, such as labor unions, and thereby limits societal opportunities. As a result, there are less resources for social consultation ${ }^{[19]}$. Furthermore, Morocco's trade union movement has been fragmented for many years and driven by the logic of conflict and combat ${ }^{[20]}$, making it impossible to lay the groundwork for a national debate based on discussion and consultation.

The predominance of small and medium-sized enterprises (SMEs) in Morocco's industrial fabric highlights a financial, institutional, and human fragility that makes implementing a structured, regulated, or even licensed CSR difficult, as it requires management methods that substitute the informal with the formal the method should be compared to the operation, the 
preparation should be compared to imagination, and the written should be compared to the oral ${ }^{[21]}$.

These reforms result in the "denaturing of the Moroccan SME ${ }^{[22]}$,since they are difficult to enforce in an economi c environment where the SME's sustainability and longterm viability are prioritized.

Employee and management training has not yet caught up to the Moroccan government's passion for CSR. University or vocational education is also governed by disciplines that emphasize competition over social cohesion.

\section{Future work}

The most important thing for our team after the CSR positioning study in Morocco, is to work on a survey to raise awareness of entrepreneurs on the strengths of the implementation of standards that promote social and environmental responsibility at the company level, in order to ensure global competition in this context of motivation and strategic monitoring.

Firstly, our team will define all of the questions for our survey, on the basis of the analysis of the data collected, our team will propose a computerized guide to motivate companies to apply ISO 26000 standards.

the aim is to ensure a positive impact on employees, society and the environment. in short, it is to encourage companies for good business practice.

\section{Conclusion}

In Morocco, corporate social responsibility has become a very important topic, thanks to the interest shown by the company, its stakeholders and civil society[23]. It is conceived as the method by which companies declare their responsibility to society and the environment in which they operate and develop. In the era of globalization, Moroccan business leaders have embarked on a CSR approach that they have integrated into their strategies, even if its application is still approximate and ambiguous. To conclude, we can say that our article shows that despite the efforts made by the Moroccan state in terms of CSR which encourages all socially responsible initiatives (e.g. INDH, environmental protection, laws and standards), its conception is still very timid.

\section{References}

1. S. Frimousse et J.M. Peretti (2015), « Regards croisés sur Engagement RSE et performance », Questions de Management (n9), Pages 65 à 89.

2. L.B. Noailles et C. Bentaleb (2014), « Chapitre26. Etat des lieux de la RSE au Maroc », Ressources humaines et responsabilités sociétales, Pages 253.

3. INDH :http://www.indh.gov.ma/fr/index.asp (Consultée dernièrement).

4. Boyer A \& Scotto M.J (2013), « Gouvernance d'entreprise et responsabilité sociale au Maroc : l'évolution de l'OCP », Management Prospective Ed. « Management \& Avenir ».

5. EXTRAIT du message royal à la troisième édition des « Intégrales de l'Investissement »,2005 http:/www.maec.gov.ma/fr/fcom.asp?num=2884\&t $\mathrm{yp}=\mathrm{dr}$.

6. Boyer A \& Scotto M.J (2013), « Gouvernance d'entreprise et responsabilité sociale au Maroc : l'évolution de l'OCP », Management Prospective Ed. « Management \& Avenir ».

7. T. Laajini, A. Cherkaoui (2020), «Engagement responsable des entreprises marocaines et territoire construit: quelle redevabilité sociétale ? Cas de l'OCP Safi »., Revue Management et Innovation.

8. J.P. Gond, et J. Igalens (2008), « La responsabilité sociale de l'entreprise », Collection Que sais-je ? Puf, Paris.

9. IGALENS J. et J.M. PERETTI. 2008. Audit social, éd. d'Organisation.

10. Z. Abbass, et M.S. Hammouchi (2020), «l'orientation des dirigeants : quel impact sur les stratégies de responsabilité sociale (RSE) poursuivies par les entreprises marocaines ?» Ed EMI, Revue Management et Innovation.

11. D. Mazutis (2013), «The CEO Effect: A Longitudinal, Multilevel Analysis of the Relationship Between Executive Orientation and Corporate Social Strategy». Article first published online : June 19, 2013; Issue published: December 1, 2013.

12. Mazutis, D., et Zintel, C. (2015). "Leadership and corporate responsibility: a review of the empirical evidence.” Annals in Social Responsibility, 1(1), 76107.

13. Pasquero, J. (2017). « La RSE : exploration d'un champ scientifique foisonnant ", in B. M'Zali, C. Hervieux, et M. M'Hamdi, (eds.), Un regard croisé d'experts et chercheurs sur la RSE : D'un contexte global au contexte de pays émergents. Montréal, Les Éditions JFD, pp. 29-73. Peterson, R. S., et Jun, M. (2009). "Perceptions on Social Responsibility." Business \& Society, 48(3), 385-405.

14. Reimer, M., Van Doorn, S., et Heyden, M. L. M. (2017). "Unpacking functional experience complementarities in senior leaders' influences on CSR strategy: a CEO-top management team approach.” Journal of Business Ethics, 1-19.

15. LAURIOL J. (2004), « Le développement durable à la recherche d'un corps de doctrine », Revue Française de Gestion, Dossier Développement Durable, Vol. 30/152, sept.-oct., p. 137-150.

16. C. Fournier, «10 Actions que Peuvent Mettre en Place les Entreprises pour le Climat », publié le 29 octobre 2015. www.youmatter.world

17. Filali-Maknassi R. (2009), «Quel avenir pour la responsabilité sociale au Maroc ? ", Droits de l'Homme et développement durable : quelle articulation? sd A. Sedjari, l'Harmattan, Paris. 
18. Mezuar A. (2002), L'entreprise marocaine et la modernité. Recherche sur les conditions de changement culturel pour un progrès durable, Casablanca Ed.

19. ETTAHIRI S. (2009), « Perception et pratique de la responsabilité sociale des entreprises au Maroc : cas du textile habillement ", Actes de la conférence internationale sur la RSE, Agadir, Maroc.

20. HAMOUMI K. (2005), « Syndicalisme et management dans les entreprises marocaines : faire du dialogue social la solution de la performance absolue des entreprises », Actes de la 23 e Université d'été de l'IAS, Lille, France.

21. TORRES O. (1997), « Pour une approche contingente de la spécificité de la PME », Revue Internationale PME, vol. 10, $\mathrm{n}^{\circ} 2$

22. EL MOUJADIDI N., KARIM K. (2009), « Développement durable et responsabilité sociale au sein de l'entreprise marocaine ", Actes de la conférence internationale sur la RSE, Agadir, Maroc.

23. Benraiss-Noailles L. \& Bentaleb C. (2014), Chapitre 26 : «Etat des lieux de la RSE au Maroc » p. 253 in « Ressources Humaines et Responsabilités sociétales ", sous la direction de Frimousse S., Igalens J., Orsoni J. \& Thevenet M., EMS.

24. Bourekkadi, S., Slimani, K., El Imrani, O., Babounia, A., Khoulji, S., \& Aboulhassane, A. (2021). Intelligent Technology Solutions at the Service of Energy Consumption Management. In E3S Web of Conferences (Vol. 234, p. 00108). EDP Sciences.

25. Alhousali, A., Bourekkadi, S., Azougagh, M., Boukhal, H., Alibrahimi, E., \& Elmahjoub, C. (2021). The role of scientific research on nuclear radiation waste management and preserving environment. In E3S Web of Conferences (Vol. 234). EDP Sciences. 